S U M A R I O

\title{
I. DossIER
}

\section{LITERATURA COLONIAL}

Raúl Marrero-Fente, Épica, fantasma y lamento: la retórica del duelo en $L a$

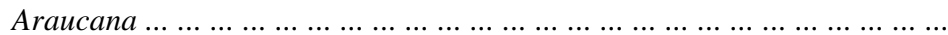

Nicole Caso, Pragmatismo y el discurso ingenioso en el Sermón de la Epifanía

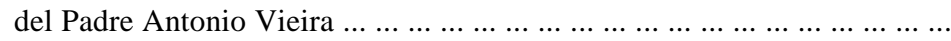

Danuta Teresa Mozejko, El letrado y su lugar en el proyecto de nación: El Periquillo Sarniento de Fernández de Lizardi ... .......................

\section{LITERATURA CUBANA}

Fernanda Macchi, Juan Francisco Manzano y el discurso abolicionista: una

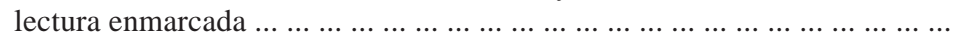
Jorge Brioso, La carne de René o el aprendizaje de lo literal ............... Alexis Candía Cáceres, Trilogía sucia de La Habana: descarnado viaje por el anteparaíso .....................................................

Nanne Timmer, La crisis de representación en tres novelas cubanas: La nada cotidiana de Zoé Valdés, El pájaro, pincel y tinta china de Ena Lucía Portela y La última playa de Atilio Caballero ... ......................

\section{EsTUDIOS}

NAncy Vogeley, Espacios públicos descolonizados: la hoja volante ............ Martín SorbilLE, El martirio del unitario en "El matadero” de Echeverría: el semblante materno como causante de la formación de su sueño-cuento .......

Juan Carlos Galdo, “Tempestad en los Andes”: alegoría y revolución en El

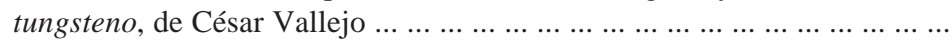

Michael Aвeyta, Catedrales, nómadas y cuerpos sin órganos: entre Gilles Deleuze y las novelas de Alberto Ruy Sánchez ... .......................

SARISSa CARneiro, La (pos)moderna Tenochtitlán: notas sobre la ciudad en Materia dispuesta de Juan Villoro ... .................................

Tania Gentic-Valencia, El relajo como redención social en Los rituales del caos de Carlos Monsiváis ........................................

Jorge Carlos Guerrero, Augusto Roa Bastos y Los conjurados del Quilombo del Gran Chaco (2001): un legado literario para la integración latinoamericana 
Andrea Jeftanovic, Perto do coração selvagem de Clarice Lispector: la infancia como temporalidad y espacio existencial .......................

Silvia G. Kurlat Ares, El lenguaje de la tribu: los códigos del rock nacional entre Charly García y Marcelo Cohen ... ... ... ...................... . . . María Fernanda Lander, La voz impenitente de la "sicaresca” colombiana ...

Paola Marín, Ética, estética y erotismo: La reflexión crítica de Jorge Gaitán Durán

\section{ENTREVISTAS}

Macarena Areco, Entrevista con Jorge Volpi: sobre el enigma del compromiso del intelectual en el lado de allá y en el de acá ... .......................

Berenice Villagomez, La contienda de una generación. Entrevista a Ignacio

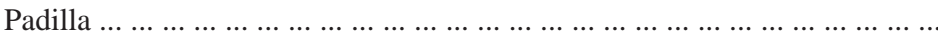

IV. NotA

Roberto Hozven, El inútil de la familia: cinco sorpresas narrativas ... ........

\section{NECROLÓGICAS}

Javier CAmpos, El poeta Gonzalo Millán (1947-2006) ... ... ... ... ... . ... . ... . .

Carlos A. Jáuregui, Eduardo Lozano (1925-2006) ... ... ... ... ................

\section{RESEÑAS}

Danny Méndez sobre Teresita Martínez-Vergne, Nation and Citizen in the Dominican Republic, 1880-1916

Rodolfo Cardona sobre Christina Komi Kallinikos, Digressions sur la métropole: Roberto Arlt, Juan Carlos Onetti, autour de Buenos Aires .... ...

Kathryn Joy McKinght sobre Santa Arias y Mariselle Melendez, eds., Mapping Colonial Spanish America. Places and Commonplaces of Identity,

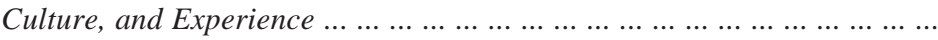

Alejandra LaERA sobre Graciela Batticuore, La mujer romántica. Lectoras, autoras y escritores en la Argentina: $1830-1870$... ....................... . . .

SANTA Arias sobre Álvaro Félix Bolaños, Elites y desplazados en el Valle del

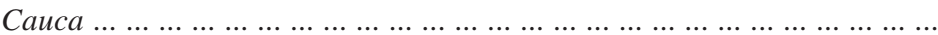

Luis Duno-GottBerg sobre Lydia Chávez, ed., Capitalism, God, and a Good Cigar.Cuba Enters the Twenty-first Century ... .........................

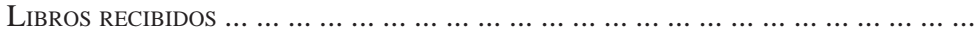

